\title{
Sustentabilidade e Responsabilidade Social Corporativa como estratégia para a competitividade na Hotelaria
}

\author{
Sustainability and Social Corporation Responsibility as a Competitive \\ Strategy in Hotels
}

\author{
Mariana de Freitas Coelho (COELHO, M. de F.) ${ }^{*}$ \\ Marlusa Gosling (GOSLING, M.) ${ }^{* *}$ \\ Carlos Alberto Gonçalves (GONÇALVES, C. A.) ${ }^{* * *}$
}

\begin{abstract}
RESUMO - Esse artigo tem como objetivo discutir a relação entre ações de sustentabilidade e responsabilidade social corporativa no âmbito da hotelaria e suas possíveis contribuições para competitividade do setor hoteleiro. O método utilizado envolveu a coleta de dados de hotéis do município de Belo Horizonte, Minas Gerais (Brasil), mediante um estudo de caso descritivo. Avaliou-se o discurso formal, o discurso pronunciado e subtendido, silenciado pelo responsável por cada hotel na interpretação dos pesquisadores. O estudo buscou descrever as ações dos dirigentes hoteleiros com reflexos causais no desempenho organizacional de maneira estratégica. As estratégias pesquisadas com ênfase foram a associação do hotel a alguma rede hoteleira ou instituição turística local; e a prática de ações relacionadas à responsabilidade social corporativa e sustentabilidade. Os fatores operacionais destacados pelos hoteleiros e identificados como indutores da competitividade dos empreendimentos foram: (1) Organização em redes e franquias; (2) Manutenção e investimento em infraestrutura e equipamentos de lazer; (3) Qualificação da mão de obra, notadamente em serviços; (4) Orientação estratégica de mercado e, (5) Ações de responsabilidade social corporativa. Finalmente, as ações sustentáveis nos hotéis pesquisados enfocam principalmente a gestão rígida de caixa, com ênfase em controle de centros de custos operacionais. A responsabilidade social corporativa e sustentabilidade apresentam menor prioridade estratégica para os gestores.
\end{abstract}

Palavras-chave: Desempenho hoteleiro; Sustentabilidade em hotelaria; Responsabilidade Social; Competitividade no setor hoteleiro.

\footnotetext{
* Graduação em Turismo e Especialização em Avaliação, Gestão e Elaboração de Projetos Sociais pela Universidade Federal de Minas Gerais (UFMG). Mestranda em Administração pela UFMG. Professora Bolsista do Curso de Design de Moda da UFMG. Endereço para correspondência: Av. Antônio Carlos, 6627. CEP: 31270-901 - Belo Horizonte - Minas Gerais (Brasil). Telefone para contato: 31 3409-7050. E-mail: marifcoelho@gmail.com

** Graduação em Ciência da Computação (Bacharelado), Mestrado em Administração e Doutorado em Administração pela UFMG. Professora Adjunta II da UFMG. Endereço para correspondência: Av. Antônio Carlos, 6627. CEP: 31270-901 - Belo Horizonte - Minas Gerais (Brasil). Telefone para contato: 31 3409-7050. E-mail: mg.ufmg@gmail.com

*** Doutorado em Administração pela Universidade de São Paulo (USP), Mestrado em Ciências em Informática pela Pontifícia Universidade Católica do Rio de Janeiro (PUC-RJ). Professor Associado da UFMG e da Universidade FUMEC nas Faculdades de Ciências Econômicas e Ciências Empresariais. Endereço para correspondência: Av. Antônio Carlos, 6627. CEP: 31270-901 - Belo Horizonte - Minas Gerais (Brasil). Telefone para contato: 31 3409-7050. E-mail: carlos@ face.ufmg.br
} 
ABSTRACT - This article aims to discuss the relationship between sustainability initiatives and corporate social responsibility within the hospitality and its possible contributions to the hospitality sector competitiveness. The method involved collecting data from hotels of Belo Horizonte, Minas Gerais (Brazil) through a descriptive case study. It was evaluated the formal speech, the pronounced speech and the "unspoken speech", silenced by the responsible of each hotel by the interpretation of the researchers. The study sought to describe the actions of hotels' leaders with causal reflections in the organizational performance of a strategic manner. The strategies researched with emphasis were the association of the hotel to any hotel chain or a local touristic institution; and the practice of actions related to corporate social responsibility and sustainability. The operational factors highlighted by hoteliers and identified as inducers of enterprises competitiveness were: (1) Organization in chains and franchising, (2) Maintenance and investment in infrastructure and leisure facilities, (3) Qualification of the workforce, especially in services and (4) Strategic market orientation and (5) Actions of corporate social responsibility. Finally, the sustainable actions in the researched hotels focus mainly on the strict cash management, with emphasis in the operational costs centers. Corporate social responsibility and sustainability is not a strategic priority to the managers.

Key words: Hotel Performance; Hotel Sustainability; Social Responsibility; Hospitality Sector Competitiveness. 


\section{INTRODUÇÃO}

A responsabilidade social corporativa pode ser entendida como a preocupação dos responsáveis por uma empresa em tomar decisões e implementar ações que contribuam tanto para o bem estar e interesses da sociedade quanto para o alcance dos objetivos da organização (DAFT, 1999; SOUZA; FERREIRA, 2010).

$\mathrm{O}$ conceito de sustentabilidade nas empresas envolve investimentos e contrapartidas para seu público interno - trabalhadores, gestores, dentre outros - e também para seu público externo como comunidade, Organizações Não Governamentais e outros (TEODÓSIO; BARBIERI; CSILLAG, 2006). Assim, responsabilidade social corporativa e sustentabilidade são temas que possuem muito em comum ao extrapolar o âmbito empresarial e inserir a sociedade no contexto da organização.

Por outro lado, autores como Ferrell, Fraedrich e Ferrell (2000) e Serpa e Fourneau (2007) sugerem que os pilares da Responsabilidade Social Corporativa consideram as dimensões filantrópica, legal, econômica e ética. Já a sustentabilidade, é abordada na academia com uma maior abrangência, envolvendo os pilares econômico, social, ambiental e cultural. (AVSI, 2011; HOFFMANN; BRAGHIROLLI; CAMPOS, 2010; SOARES; SOUSA, 2010).

Entretanto, estudos no setor turístico ainda enfocam a noção de sustentabilidade, uma vez que, sobretudo a esfera ambiental envolve diversas preocupações tanto da academia como das comunidades turísticas. Deste modo, este trabalho adota uma visão multifacetada da sustentabilidade que vai além da perspectiva econômica e comercial, já que os impactos do turismo necessitam de uma abordagem dos níveis de planejamento, política e entrega de serviços (SHAH, 2011).

Segundo Ioncica et al. (2008), a busca por atividades sustentáveis só foi incluída recentemente como estratégia de competitividade na hoteleira. Assim, os autores sugerem que os hotéis são encorajados a adotar novos métodos para proteger o meio ambiente e apoiar a comunidade local.

Vieira e Hoffmann (2010) apontam que as questões relacionadas aos cuidados sobre a preservação do ambiente externo onde as empresas atuam são muito discutidas na indústria, porém há uma negligência no setor de serviços, a citar o setor turístico e 
mais especificamente a hotelaria. Ainda, Souza e Ferreira (2010) reiteram que para as empresas que atuam no setor turístico entendam as formas adequadas de minimizar os impactos da atividade, é necessária a utilização de conceitos como a responsabilidade social corporativa e sustentabilidade.

A necessidade da responsabilidade social corporativa também ser abrangida nesse trabalho se dá em função do tema possuir uma base da literatura internacional que a conecta à competitividade na hotelaria, a citar Merwe e Wörke (2007) e Holjevac (2010) e em seu maior enfoque interno na gestão hoteleira em comparação com a sustentabilidade.

Ainda, manter a competitividade das empresas de maneira sustentável envolve a excelência na condução dos negócios, o envolvimento em questões comunitárias locais, a cooperação com a cadeia produtiva e com os concorrentes e por fim, o envolvimento com questões mais globais e parcerias com organismos nacionais e internacionais. (KAKU, 1997; SCHROEDER; SCHROEDER, 2004; TEODÓSIO; BARBIERI; CSILLAG, 2006).

Contudo, a maioria das empresas continua a encarar conceitos como a responsabilidade social e sustentabilidade como sendo alcançáveis somente aos ricos ou a grandes empresas (HANDY, 2005) ou utilizam o conceito apenas como discurso sem modificar seus processos de produção (KEINERT, 2008). Flecha (2007) assume que uma das grandes dificuldades da prática de responsabilidade social corporativa é a articulação interorganizacional. Ou seja, a desarticulação entre as empresas, ou entre a empresa e a comunidade é um desafio para a consolidação de parcerias que desenvolvam atividades de desenvolvimento sustentável.

A maioria dos programas de contribuição empresarial é prolixa: "Em vez de estarem vinculados a objetivos sociais ou empresariais bem formulados, as contribuições muitas vezes refletem crenças e valores pessoais de executivos ou funcionários.” (PORTER; KRAMER, 2005, p. 136) . Assim sendo, Porter e Kramer (2005) sugerem que as empresas reavaliem onde enfocar suas medidas de sustentabilidade e como exercê-la.

Diante dessa problemática, é evidente a importância de se discutir a relação de firmas hoteleiras com variáveis que contribuam para a manutenção da competitividade. Esse estudo detalha como a responsabilidade social corporativa é uma temática que está 
sendo abordada na gestão do setor hoteleiro de Belo Horizonte. Nesse sentido, foi proposta a pergunta: Quais fatores poderiam contribuir para o desempenho da hotelaria considerando a sustentabilidade e a responsabilidade social corporativa?

Ao responder esse problema, a pesquisa demonstrou tendências de como o setor hoteleiro tem enfocado suas ações para garantir a competitividade no mercado. Também, especificou como a responsabilidade social corporativa pode possuir um papel de destaque para a geração de desempenho superior, que ainda é um desafio para o setor. Tendo em vista que se trata de um tema de interesse público e que não compromete as firmas estudadas, os nomes dos hotéis foram divulgados.

\subsection{VANTAGEM COMPETITIVA E DESEMPENHO}

De acordo com Castells (2000), a competição consiste na busca de um desempenho superior entre empresas no mercado. A vantagem competitiva é um dos argumentos utilizados para explicar o desempenho superior de algumas empresas em relação a outras. Contudo, frequentemente esse argumento é simplificado em rentabilidade superior (BRITO; BRITO, 2012).

Segundo Brito e Brito (2012) a multidimensionalidade do desempenho organizacional é reconhecida por vários autores como Combs, Crook, Shook (2005) ${ }^{1} \mathrm{e}$ Venkatraman e Ramujam $(1986)^{2}$. Ao considerarem o desempenho em relação a suas dimensões, tem-se: (1) Dimensão Organizacional, que é mais ampla e envolve a eficácia organizacional; (2) Dimensão Financeira, a qual abrange a rentabilidade da empresa, sendo de grande importância para a sobrevivência da mesma; (3) Dimensão operacional, que envolve aspectos complementares como tecnologia, inovação para a criação de valor, qualidade, responsabilidade social coorporativa, dentre outros (Figura 1).

Esse trabalho possui um enfoque na dimensão operacional do desempenho. Ao considerar que a dimensão operacional não coloca a rentabilidade financeira como enfoque principal, os indicadores dessa dimensão podem ser vistos como vantagens

\footnotetext{
${ }^{1}$ COMBS, J. G; CROOK, T. R; SHOOK, C. L. The dimension of organizational performance and its implications for strategic management research. In: KETCHEN, D. J; BERGH, D. D. (Orgs). Research methodology in strategy and management. San Diego: Elsevier, 2005. p. 259-286.

${ }^{2}$ VENKATRAMAN, N.; RAMANUJAM, V. Measurement of business performance in strategy research: a comparison of approaches. Academy of Management Review, v. 11, n. 4, p. 801-814, 1986.
} 
competitivas temporárias. Isto é, nem toda estratégia de desempenho operacional reverte diretamente em um aumento nos lucros ou maior competitividade da empresa. A vantagem competitiva da dimensão operacional perdura até que exista a imitação ou cópia dos benefícios dessa vantagem por uma empresa concorrente (BARNEY; CLARK, 2007) ou até a saturação do cliente.

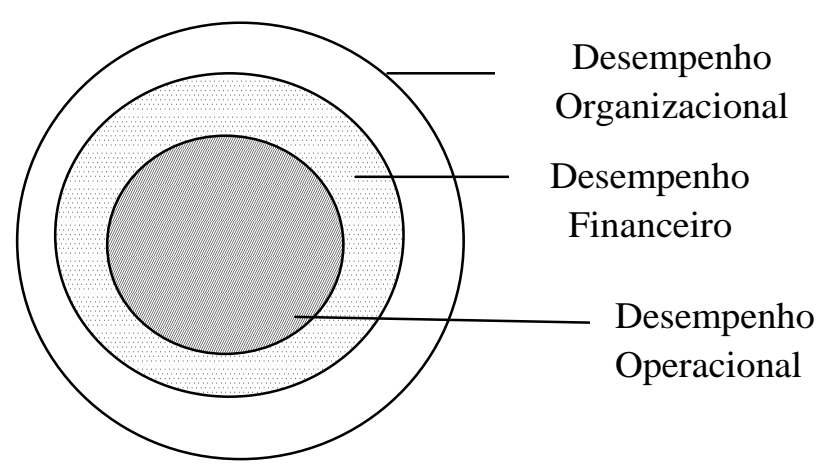

FIGURA 1 - DIMENSÕES DO DESEMPENHO ORGANIZACIONAL

Fonte: Autores, baseado em Brito e Brito (2012).

Uma vantagem competitiva sustentável para Barney e Clark (2007) é orientada para o longo prazo, atinge resultados duradouros e demanda a competência da firma para que a estratégia permaneça mesmo depois que os esforços de outras firmas para duplicar essa vantagem competitiva acabem.

A crescente competitividade entre as organizações desencadeou novas preocupações e diversas estratégias empresariais para a manutenção das empresas no mercado. Uma das alternativas encontradas pelas empresas para garantir um bom desempenho é a organização em redes. Para Gameiro (2008) as empresas tendem a adotar formas de organização mais globais a fim de continuarem competitivas. Ainda, considera que a chave para manter vantagens competitivas estaria na capacidade de construir e manter redes entre organizações.

O conceito de redes sociais não possui um único significado. De uma forma mais ampla, uma rede pode significar o conjunto de nós interconectados onde há uma relação de dependência entre o nó (organização) e o tipo de rede onde ele está inserido (CASTELLS, 2000). A utilização do conceito de redes sociais para a organização no ambiente de negócios se relaciona com a percepção de que atuar de forma isolada pode reduzir as condições de sobrevivência e desenvolvimento das firmas (OLIVEIRA; GONÇALVES, 2011). A organização em rede pressupõe a existência de diversos tipos 
de enlace que podem ser formados entre os nós (por exemplo, empresas de um mesmo setor e de setor complementares interconectadas). Esse conjunto de empresas organizadas em rede podem formar enlaces mais próximos ou mais distantes e consequentemente uma teia global de alianças estratégicas que formam uma constelação (conjunto de nós).

Tendo em vista o relacionamento interorganizacional, parte-se da premissa teórica de que empresas organizadas em rede são gregárias em um nível mais amplo, apesar de competirem no nível de negócio (PORTER, 1998; HITT; IRELAND; HOSKISSON, 2003). Por exemplo, dois hotéis da Rede Accor localizados em Belo Horizonte na região da Savassi podem competir em nível de negócio em relação à captação de seus clientes. Contudo, sob uma abordagem mais global, eles utilizam a mesma plataforma de reserva online, mesmas estratégias de marketing, e deste modo, podem aproveitar melhor os seus recursos e reduzir custos de marketing.

Esse exemplo remete à noção de quais seriam as vantagens de se organizar em rede e porque uma empresa consideraria essa agregação como benéfica. Dentre algumas alternativas, pode-se citar: (1) redução do stress; (2) compartilhamento de riscos (GAMEIRO, 2008); (3) criação de barreiras para novos entrantes (OLIVEIRA; GONCALVES, 2011); (4) criação de barreiras contra produtos substitutos (OLIVEIRA; GONCALVES, 2011); (5) redução do poder de barganha dos clientes; (6) redução do poder de barganha dos fornecedores; (7) compartilhamento de informações estratégicas (HOFFMANN; BRAGUIROLLI; CAMPOS, 2010); (8) redução de custos operacionais e administrativos (PROSERPIO, 2007), dentre outros.

No contexto de empresas turísticas, Hoffmann, Braguirolli e Campos (2010), citam que a empresa turística é considerada complexa e raramente possui condições de atender a todas as demandas dos turistas como necessidades básicas, infraestrutura de suporte e infraestrutura turística. Por isso, é comum o alinhamento entre empresas turísticas e empresas complementares que apoiam o turista no destino como meios de hospedagem, empresas de alimentos e bebidas, empresas de transporte, dentre outras. Assim, o relacionamento entre empresas pode maximizar resultados e melhorar o desempenho por meio de estratégias conjuntas (HOFFMANN; BRAGUIROLLI; CAMPOS, 2010). 
Outra possibilidade de organização em rede na hotelaria seriam as redes hoteleiras ou franquias (PROSERPIO, 2007), as quais podem ser redes com atuação internacional, regional ou local. Há também instituições que apoiam as atividades turísticas e podem servir como boas fontes de geração de maior competitividade para o destino turístico e também para o empreendimento hoteleiro quando utilizado de maneira estratégica, a partir, por exemplo, da criação de parcerias e alianças estratégicas.

Enfim, também no turismo a configuração interna das empresas é relevante e no meio hoteleiro tem se desenvolvido no sentido de buscar diferenciar seus serviços a fim de causar impacto na percepção do turista sobre a empresa (HOFFMANN; BRAGUIROLLI; CAMPOS, 2010). Proserpio (2007) destaca que a entrada de redes hoteleiras internacionais no Brasil teve o efeito imediato de elevar a competitividade, aumentar a qualidade dos serviços de hospedagem, diversificar a clientela e profissionalizar a gestão. Portanto, a organização em rede pode aumentar a vantagem competitiva das empresas hoteleiras.

Segundo Holjevac (2010), a produtividade e competitividade determinam a riqueza e o desenvolvimento de uma nação e também da hotelaria, assim como a qualidade de vida dos empregados, clientes e proprietários em uma sociedade. Nessa perspectiva interna, a sustentabilidade é outro tema que tem ganhado relevância para a competitividade dos empreendimentos hoteleiros principalmente em função da globalização (MUNCK; MUNCK; BORIM-DE-SOUZA, 2011). De acordo com Munck, Munck e Borim-De-Souza (2011) a mudança na noção de sustentabilidade nas empresas passou de uma visão puramente financeira almejando bom patrimônio e lucros crescentes, para uma abordagem dos três Ps (Pessoas, Planeta e Lucro). Em outras palavras, a organização sustentável da atualidade não deveria se ater apenas ao quesito lucro, mas também ao desenvolvimento social e a preservação ambiental.

\subsection{RESPONSABILIDADE SOCIAL CORPORATIVA E SUSTENTABILIDADE NA HOTELARIA}

A importância de se discutir temas como responsabilidade social corporativa e sustentabilidade no setor turístico está relacionada às transformações e impactos das 
empresas do setor no ambiente em que atuam. Nesse sentido, empresas turísticas são pressionadas a contribuir para a valorização da cultura local, respeito ao meio ambiente, geração de emprego e renda, dentre outros (SOUZA; FERREIRA, 2010).

Ao avaliar a sustentabilidade, um empreendimento necessita definir critérios que caracterizem esse conceito para materializar os indicadores de sustentabilidade. Com isso, os aspectos ambiental, econômico e sociocultural do desenvolvimento sustentável e as práticas de gestão são aplicáveis ao contexto turístico (SOARES; SOUSA, 2010).

A sustentabilidade é um conceito sistêmico, relativo à continuidade de aspectos econômicos, sociais, culturais e ambientais da sociedade (HOFFMANN; BRAGUIROLLI; CAMPOS, 2010). Apesar da amplitude do conceito de sustentabilidade, a dimensão teórica mais explorada quanto à sustentabilidade em empreendimentos hoteleiros diz respeito à gestão ambiental e está intimamente conectada à responsabilidade social corporativa.

Dentre as ações do âmbito econômico da responsabilidade social corporativa, Souza e Ferreira (2010) citam: (1) a remuneração justa aos fornecedores, empregados, sócios e acionistas; (2) relacionamento honesto com consumidores; (3) utilização racional de recursos naturais e (4) qualidade adequada dos serviços prestados. Ainda, Coelho (2009) destaca a geração de oportunidades de emprego e capacitação de mão de obra local e a utilização de fornecedores da região.

No âmbito cultural, Borges (2010) chama a atenção para a necessidade de manter a cultura de um local e promover a imagem de seus valores, estilo de vida, comportamento, entre outros. Assim, seria possível reforçar a identidade local ao conservar as autenticidades da cultura do destino turístico. E no âmbito social, a autora sugere o apoio a programas voltados para a comunidade como Organizações Não Governamentais e o desenvolvimento da qualidade de vida no destino.

De acordo com Ribeiro (2008), a gestão ambiental organizacional pode ser entendida como um conjunto de ações e práticas administrativas que buscam a eliminação ou minimização de impactos no meio ambiente. Na hotelaria, seu objetivo primordial deve ser a constante busca pela melhoria da qualidade ambiental dos serviços por meio de um aperfeiçoamento contínuo do sistema de gestão ambiental de acordo com as políticas do estabelecimento. Os impactos gerados por tal política podem variar 
de acordo com o empreendimento e seu respectivo porte, bem como o interesse e a capacidade de gestão e de envolvimento da equipe.

Ainda segundo Ribeiro (2008) são diversas as ações ambientais desenvolvidas no setor hoteleiro, de forma que elas apresentam maior expressividade para um hotel quando combinadas ao invés de quando se trata de iniciativas isoladas. Citam-se algumas ações como: (1) Uso de economizadores de energia nas unidades habitacionais; (2) Uso de dispositivo de presença e sensores; (3) Uso de lâmpadas econômicas; (4) Uso de redutores de vazão de água nas torneiras; (5) Uso de Torneiras Automáticas; (6) Tratamento adequado dos efluentes gerados; (7) Sistema de compostagem de resíduos; (8) Coleta Seletiva de Lixo; (9) Diminuição da lavagem diária de roupa e substituição de produtos que agridem ao meio-ambiente. Para Hsieh (2010), a implantação da sustentabilidade em meios hoteleiros deve envolver também tecnologias alternativas para mitigar impactos ambientais.

Uma tendência que vem sido observada no mercado diz respeito a consumidores mais sensíveis às preocupações com a sustentabilidade (SERPA; FOURNEAU, 2007). A resposta do setor hoteleiro abrange investimentos em medidas sustentáveis e busca por certificações ambientais e selos de qualidade (COELHO, 2009). No entanto, é difícil fazer com que medidas de sustentabilidade e responsabilidade social corporativa sejam visíveis e aplicáveis ao consumidor final. Além disso, implementar serviços sustentáveis no mercado ainda é um desafio para empresas de qualquer setor, inclusive o turístico.

Souza e Ferreira (2010) afirmam que há poucas pesquisas acadêmicas no Brasil que comprovem que o consumidor brasileiro recompense uma organização socialmente responsável e prefira comprar da mesma. Para Borges (2010), a responsabilidade social nos negócios pode contribuir para a redução de gastos, multas e preservação da imagem institucional da empresa. E ainda, por meio dessas ações citadas, a responsabilidade social corporativa pode contribuir para a competitividade das empresas do setor. 


\section{PROCEDIMENTOS METODOLÓGICOS}

Este estudo é composto de uma pesquisa exploratória que visou avaliar hotéis de Belo Horizonte, Minas Gerais quanto a sua responsabilidade social corporativa e sustentabilidade. Foi feito um estudo de múltiplos casos e a primeira etapa metodológica envolveu a pesquisa bibliográfica e revisão teórica dos principais conceitos adotados no trabalho.

Por meio de pesquisa documental em instrumentos como sites específicos de cada hotel, material oficial de divulgação e visitas a hotéis localizados no município de Belo Horizonte foram avaliadas as ações dos hotéis que poderiam se relacionar ao desempenho organizacional, enfatizando a associação a alguma rede hoteleira ou instituição turística local; e a prática de ações relacionadas à responsabilidade social corporativa.

Após a identificação de 19 hotéis que praticavam alguma medida de responsabilidade social corporativa, os mesmos foram selecionados para o estudo. Em um segundo momento, foi feita uma divisão entre hotéis organizados em rede e hotéis independentes, os quais afirmavam realizar alguma medida sustentável.

Como sugere Soares $(2004$, p. 8) buscou-se avaliar os três diferentes tipos de discursos sobre responsabilidade social corporativa no objeto de estudo. $\mathrm{O}$ discurso explicitado através de sites e documentos formais do hotel; o discurso pronunciado reservadamente por meio de entrevistas; e o discurso não dito, a partir de uma análise crítica dos discursos explicitados e pronunciados reservadamente.

Foram aplicadas 12 entrevistas a um responsável ou pelo hotel ou pela rede (proprietário, gerente ou responsável de marketing) com o objetivo de avaliar as iniciativas de responsabilidade social corporativa e sustentabilidade nos hotéis nos âmbitos social, cultural, ambiental e econômico conforme propõe Hoffmann, Braguirolli e Campos (2010). O questionário semiestruturado das entrevistas considerou as seguintes perguntas: 1) Quais as principais ações do Hotel para manter a competitividade no mercado? 2) Existe alguma ação de responsabilidade social corporativa que vise manter a competitividade do Hotel? 3) Quais as iniciativas são ou pretendem ser tomadas pelo Hotel em relação à sustentabilidade? 3.1) No âmbito econômico? 3.2) No âmbito social? 3.3) No âmbito cultural? 3.4) No âmbito ambiental? 
4) Quais os principais desafios e dificuldades enfrentados pelo Hotel para a manutenção de ações sustentáveis?

O critério utilizado para a aplicação de entrevistas foi por conveniência, de acordo com a disponibilidade dos responsáveis. Finalmente, foi feita a avaliação dos resultados e discutidas as principais proposições da pesquisa em relação à literatura abordada.

\section{FATORES OPERACIONAIS QUE AFETAM O DESEMPENHO DA HOTELARIA}

A hotelaria de Belo Horizonte tem acompanhado algumas tendências globais como a ascensão das redes hoteleiras e de hotéis econômicos, além de estar sendo pressionada a se preparar mais, investir em sua infraestrutura e buscar uma equipe mais qualificada em função de um mercado cada vez mais exigente (COELHO, 2009).

Por meio de pesquisa documental e de entrevistas aos gestores dos hotéis, foram identificados cinco fatores que podem influenciar diretamente no desempenho operacional da rede hoteleira do município de Belo Horizonte. Dentre eles: (1) Organização em redes e franquias; (2) Manutenção e investimento em equipamentos; (3) Qualificação da Mão de Obra; (4) Orientação Estratégica de mercado e (5) Ações de Responsabilidade Social Corporativa.

Organização em Redes e Franquias - Aspectos como localização, história do hotel e tipo de gestão são importantes fatores que interferem no desempenho operacional dos empreendimentos hoteleiros (XIAO; O’NEILL; MATTILA, 2012).

Proserpio (2007) sugere que não há uma competição acirrada entre hotéis em rede e hotéis individuais no Brasil, no entanto, para manter sua competitividade, hotéis individuais devem procurar a diferenciação de seus serviços. Contudo, Xiao, O’Neill e Mattila (2012), encontraram que a participação de hotéis em franquias, empresas de gestão hoteleira e redes hoteleiras influenciam positivamente o desempenho da hotelaria. Por outro lado, a pesquisa de Xiao, O’Neill e Mattila (2012) alega que o principal fator que contribui para o desempenho superior da hotelaria é o papel dos proprietários de hotéis que implementam estratégias diversas que influenciam em seus 
hotéis. Assim, a autonomia de gestão dos proprietários de hotéis tem um grande peso para a gestão de hotéis individuais.

Em relação a redes entre hotéis e outras instituições turísticas, há de se destacar que há uma tendência de hotéis fazerem parte das associações hoteleiras de Belo Horizonte. Conforme o website da Associação Brasileira da Indústria de Hotéis de Minas Gerais (ABIH-MG, 2013) ${ }^{3}$, existem 103 meios de hospedagem legalizados em Belo Horizonte. Avaliando os 49 hotéis de Belo Horizonte associados à ABIH- MG; 26 são estabelecimentos individuais, e 23 empreendimentos pertencem a algum tipo de rede (internacional, regional ou local).

O Conventions \& Visitors Bureau de Belo Horizonte - BH CV\&B possui entre seus associados hotéis, empresas de eventos, agências de viagens, restaurantes, empresas de táxi, dentre outros (BH CV\&B, 2013) ${ }^{4}$. Ao avaliar os hotéis associados, apenas 10 são hotéis independentes e 23 hotéis fazem parte de redes hoteleiras. Todos os 33 hotéis associados do município de Belo Horizonte cobram uma taxa de turismo diária ao hóspede, de forma que o valor varia de acordo com o padrão do hotel, e repassa essa quantia ao BH C\&VB para reinvestimentos no setor (COELHO, 2009).

Com base na literatura apresentada e as entrevistas dos hoteleiros, a associação em rede entre hotéis e seus concorrentes ou entre hotéis e outras instituições é importante para que os desafios e problemas comuns sejam supridos com maior facilidade. Ainda, conforme Oliveira e Gonçalves (2011), a organização em rede proporciona a criação de uma vantagem competitiva e aumento do nível de profissionalização do gerenciamento dos hotéis como um todo, inclusive daqueles com características de gestão familiar ou individual. Outro benefício mais amplo demonstrado pelas parcerias com o $\mathrm{BH} \mathrm{C} \& \mathrm{VB}$ seria o fortalecimento do destino turístico.

Manutenção e investimento em equipamentos - Outro exemplo de diferenças de gestão hoteleira é a dificuldade de manutenção dos equipamentos e investimentos no hotel. Conforme Coelho (2009), hotéis tombados e considerados patrimônio cultural enfrentam dificuldades para reforma em função da necessidade de manutenção dos

\footnotetext{
${ }^{3}$ Associação Brasileira da Indústria de Hotéis de Minas Gerais- ABIH MG

Disponível em: <http://www.abihmg.com.br/abih_novo/associados2.asp>. Acesso em: 17/07/2013.

${ }^{4}$ Belo Horizonte Convention\&Visitors Bureau - BH C\&VB

Disponível em: <http://www.bhcvb.com.br/associados/>. Acesso em: 17/07/2013.
} 
traços característicos de alguns hotéis. A autora cita, por exemplo, barreiras enfrentadas pelo Hotel Sorrento e pelo Brasil Palace Hotel para a alteração da fachada externa dos mesmos (COELHO, 2009).

Além disso, hotéis enfrentam falta de espaço para estacionamento e espaços de eventos, demandas apontadas por alguns hoteleiros entrevistados como cada vez mais crescentes da hotelaria moderna em Belo Horizonte. Portanto, a limitação espacial, limitação de recursos financeiros e dificuldades legislativas são fatores que interferem na competição da hotelaria.

Qualificação da Mão de Obra - Conforme Holjevac (2010) possuir uma equipe preparada para atender um mercado exigente é um fator que determina a competitividade da hotelaria. Um exemplo notado foi a presença de profissionais com contato direto com o cliente que falam idiomas estrangeiros em hotéis de classificação mais luxuosa como: Rede Royal, Quality e Clarion, Othon e Ouro Minas.

Ainda, poucos hotéis destacaram o investimento em cursos e treinamentos internos, a citar Royal Golden, Royal Savassi e Pampulha Flat. O responsável pelo Hotel Sorrento destacou que cursos específicos para o setor não preparam seus alunos devidamente para hotéis de pequeno porte, tendo em vista que a demanda desses hotéis é diferenciada.

Assim sendo, a qualificação da mão de obra e treinamento específico do setor, em conformidade com a categoria do hotel, se mostra como um importante fator que influencia no desempenho operacional da hotelaria.

Orientação Estratégica de mercado - Segundo Tung, Cheng e Wu (2009) a reputação e a localização são fatores impactantes sobre a imagem geral de um hotel. Em relação à imagem do hotel, alguns gestores dos hotéis econômicos do centro de Belo Horizonte relataram possuir dificuldades em efetuar grandes divulgações e elaborar um plano de marketing para promover o meio de hospedagem. Também foi mencionado não ser comum a existência de pesquisas de opinião dentre os hotéis econômicos, de forma que essa troca de experiência entre cliente e hoteleiro acontece de forma mais informal, através do contato direto com o cliente. Ademais, grande parte dos hotéis de rede se localizam em regiões reconhecidas pela população da cidade como nobres: a Savassi (Clan Villa Ema, Royal Golden, Royal Savassi) e o Bairro de Lourdes (Clarion Lourdes). 
Constatou-se que todos os hotéis pesquisados possuem website na internet, apesar de muitos apresentarem sites simples ou com informações desatualizadas. Nesse sentido, há espaço para a atuação estratégica decididas por profissionais-chave orientadas para o mercado e para a manutenção da competitividade dos hotéis quando considerados seus concorrentes locais.

Responsabilidade Social Corporativa - Dentre os âmbitos de responsabilidade social corporativa está o ambiente interno da corporação (AVSI, 2011). A responsabilidade social corporativa pode contribuir para a competitividade hoteleira, através da redução de gastos, reforço da imagem da empresa e geração de retorno econômico, sem perder de vista as questões ambientais e socioculturais (BORGES, 2010).

Em relação específica à responsabilidade corporativa relacionada à gestão ambiental hoteleira, Vargas et al. (2011) citam que os benefícios de utilizar o sistema de gestão ambiental pode incrementar a rentabilidade por meio da redução de custos, proteção de uma melhor imagem corporativa e ter uma garantia em relação a terceiros de diminuir riscos ambientais. Para os autores, a importância de integrar a gestão ambiental à estrutura organizacional dos hotéis aborda três principais aspectos: 1) possibilidade de a empresa ser mais rentável e melhorar sua imagem corporativa; 2) cumprimento das normas e leis ambientais, evitando multas e sanções; e 3) prática voluntariosa que se estabelece em função da consciência e compromisso que o hotel tem com seu entorno natural. Como esse tema é ainda pouco explorado na hotelaria além da gestão ambiental, optou-se por se aprofundar no assunto e descobrir as ações que estavam sendo realizadas por hotéis de Belo Horizonte no próximo tópico.

\section{AVALIAÇÃO DOS RESULTADOS}

Avaliando o discurso explicitado de maneira formal nos sites oficiais e no material de divulgação dos hotéis pesquisados, a ênfase dada às questões de Responsabilidade Social e Sustentabilidade apresentou-se como quase inexistente. Apenas o site da Rede Atlântida (Hotéis Clarion e Quality) possuía link com o tema específico de Responsabilidade Social onde divulgava seu projeto em parceria com a 
Childhood Brasil. Além desse caso, apenas o Brasil Palace Hotel destacava em seu site sua história e itens como a importância do estilo arquitetônico do hotel e de sua cultura para a cidade de Belo Horizonte.

Quando os hotéis foram visitados, o discurso explicitado de responsabilidade social e sustentabilidade, in loco, pôde ser encontrado no Clarion e Quality por meio de folders na recepção do hotel; aviso nos quartos do Othon Palace e Via Contorno sobre possibilidade de envolvimento do hóspede na economia de água. Além disso, outros itens, sobretudo de cunho ambiental, podiam ser notados por hóspedes em alguns hotéis como uso de cartões de economia de energia e sensores de presença, a citar o Royal Golden e Royal Savassi. Contudo, não havendo destaque formal por escrito desses elementos aos hóspedes.

O discurso pronunciado está descrito nos quadros 1 e 2 , demonstrando que apesar de pouco ser dito formalmente, as ações são mais abrangentes do que se é dito no discurso explicitado. A partir dos quadros apresentados é possível perceber quais as dimensões que vem sofrendo maior ênfase da rede hoteleira local e quais atividades estão sendo desenvolvidas. Além disso, é possível avaliar os diferentes enfoques entre hotéis organizados em rede e hotéis individuais (Quadros 1 e 2).

QUADRO 1 - RESPONSABILIDADE SOCIAL CORPORATIVA EM HOTÉIS DE REDE DE BELO HORIZONTE

\begin{tabular}{|c|c|c|c|c|l|}
\hline HOTEL & Econômico & Social & Cultural & Ambiental & $\begin{array}{l}\text { Principais Medidas de } \\
\text { Responsabilidade Social Corporativa }\end{array}$ \\
\hline $\begin{array}{c}\text { Clan Villa } \\
\text { Emma }\end{array}$ & $\mathrm{X}$ & $\mathrm{X}$ & $\begin{array}{l}\text { Foco em redução de gastos de água e luz } \\
\text { e conscientizção dos hóspedes. Sistema } \\
\text { de aquecimento solar e reutilização de } \\
\text { água da chuva. Doações para instituições } \\
\text { de caridade. }\end{array}$ \\
\hline $\begin{array}{c}\text { Clarion } \\
\text { Lourdes }\end{array}$ & & $\mathrm{X}$ & & $\begin{array}{l}\text { Foco na proteção de crianças e } \\
\text { adolescentes contra a exploração sexual e } \\
\text { conscientização dos hóspedes }\end{array}$ \\
\hline $\begin{array}{c}\text { Differential } \\
\text { Flat }\end{array}$ & & $\mathrm{X}$ & Economia de luz e reutilização de papel. \\
\hline $\begin{array}{c}\text { Forum } \\
\text { Apart Hotel }\end{array}$ & & $\mathrm{X}$ & Economia de luz e reutilização de papel. \\
\hline $\begin{array}{c}\text { Boulevard } \\
\text { Express }\end{array}$ & & $\mathrm{X}$ & $\begin{array}{l}\text { Economia de água e luz. Sistema de } \\
\text { aquecimento solar e sistema de redução } \\
\text { de gastos com luz. }\end{array}$ \\
\hline $\begin{array}{c}\text { Othon } \\
\text { Palace Hotel }\end{array}$ & & $\mathrm{X}$ & $\begin{array}{l}\text { Economia de água e luz; conscientização } \\
\text { dos hóspedes e apoio a instituições de } \\
\text { caridade; quartos adaptados para pessoas } \\
\text { com deficiência. }\end{array}$ \\
\hline
\end{tabular}

Continua... 
Continuação...

\begin{tabular}{|c|l|l|l|l|}
\hline $\begin{array}{c}\text { Quality } \\
\text { Hotel }\end{array}$ & $\mathrm{X}$ & & & $\begin{array}{l}\text { Foco na proteção de crianças e } \\
\text { adolescentes contra exploração sexual e } \\
\text { conscientização dos hóspedes. }\end{array}$ \\
\hline $\begin{array}{c}\text { Royal } \\
\text { Golden } \\
\text { Hotel }\end{array}$ & & $\mathrm{X}$ & $\begin{array}{l}\text { Reciclagem, de forma que o valor obtido } \\
\text { com a reciclagem é reinvestido em } \\
\text { benefícios para os funcionários do hotel. }\end{array}$ \\
\hline $\begin{array}{c}\text { Royal } \\
\text { Savassi } \\
\text { Boutique } \\
\text { Hotel }\end{array}$ & & $\mathrm{X}$ & $\begin{array}{l}\text { Economia de luz e água; sistemas de } \\
\text { sensor de presença e controle do uso de } \\
\text { água; conscientização de hóspedes, } \\
\text { reciclagem. }\end{array}$ \\
\hline
\end{tabular}

Fonte: Autores.

Ações Econômicas - De maneira geral, o pilar econômico da Responsabilidade Social Corporativa não foi enfatizado com constância pelos gestores dos hotéis pesquisados. O emprego de mão de obra local e oportunidade de emprego a pessoas sem experiência anterior foram ações mencionadas. Houve também gestores que manifestaram se preocupar com a qualificação da mão de obra, fator operacional que pode contribuir para a competitividade hoteleira.

Ações Sociais - O fator social se mostrou muito ligado a situações de caráter assistencialista e filantrópico (pilar da Responsabilidade Social Corporativa), como doação de objetos e auxílio financeiro a creches, asilos e outras instituições carentes. Houve também o relato de que alguns hotéis de rede desenvolvem projetos mais abrangentes. No entanto, muitos desses projetos são desenvolvidos pontualmente e afetam os hotéis de Belo Horizonte de maneira mais restrita. Mesmo assim, há a possibilidade de participação do hóspede e conscientização do mesmo sobre a causa, mesmo que de forma sutil como a utilização de folders. Outra iniciativa que merece destaque foi a de investimento em áreas comuns e unidades habitacionais acessíveis. Apesar de se tratar de uma norma, poucos hotéis de fato seguem a legislação que garantiria acesso a pessoas com deficiência a áreas comuns do hotel e quarto adaptado, contrariando o pilar legal da Responsabilidade Social Corporativa. Uma possibilidade apontada por um dos gestores se relaciona aos altos investimentos necessários para oferecer um ambiente acessível, merecendo aprofundamento em pesquisas futuras.

Ações Culturais - Foram destacados aspectos relacionados à conservação do edifício e de artigos e objetos de época, além de apoio a entidades culturais. Também foram encontrados relatos de que alguns hotéis se preocupam com a manutenção de 
alguns aspectos históricos como fachada, móveis originais de época e artigos de decoração.

Ações Ambientais - Medidas ambientais na hotelaria da capital mineira se relacionam principalmente à economia de água e luz, além de reciclagem de alguns materiais. Trata-se de uma das poucas estratégias que pode envolver diretamente o hóspede, através, por exemplo, da opção de utilizar ou não uma toalha por dia para minimizar os gastos com água. Constatou-se haver hotéis que utilizam sistema de aquecimento solar e sistema de controle de energia, como um cartão que possibilita que a luz e o ar condicionado só sejam ativados enquanto o hóspede estiver no quarto. Também, que alguns hotéis visitados estavam investindo na modernização de equipamentos como frigobares, televisões e sensores de presença.

QUADRO 2 - RESPONSABILIDADE SOCIAL CORPORATIVA EM HOTÉIS INDIVIDUAIS DE BELO HORIZONTE

\begin{tabular}{|c|c|c|c|c|c|}
\hline HOTEL & Econômico & Social & Cultural & Ambiental & $\begin{array}{l}\text { Principais Medidas de Responsabilidade } \\
\text { Social Corporativa }\end{array}$ \\
\hline $\begin{array}{l}\text { Brasil } \\
\text { Palace } \\
\text { Hotel }\end{array}$ & $\mathrm{X}$ & $\mathrm{X}$ & $\mathrm{X}$ & $\mathrm{X}$ & $\begin{array}{l}\text { Preservação do patrimônio histórico-cultural; } \\
\text { economia de água e luz através de sensores de luz e } \\
\text { sistema de aquecimento solar; oportunidade para } \\
\text { profissionais locais, inclusive idosos e jovens sem } \\
\text { experiência anterior. }\end{array}$ \\
\hline $\begin{array}{c}\text { Dayrell } \\
\text { Hotel }\end{array}$ & $X$ & & & $\mathrm{X}$ & $\begin{array}{l}\text { Oportunidade de empregos para jovens sem } \\
\text { experiência anterior; reutilização de resíduos } \\
\text { sólidos através de doações. }\end{array}$ \\
\hline $\begin{array}{l}\text { Frimas } \\
\text { Apart } \\
\text { Hotel }\end{array}$ & & & & $\mathrm{X}$ & $\begin{array}{l}\text { Economia de água e luz. Poço artesiano e sistema } \\
\text { eletrônico de redução de gastos com luz. }\end{array}$ \\
\hline $\begin{array}{c}\text { Apart } \\
\text { Saint } \\
\text { Martin }\end{array}$ & & $\mathrm{X}$ & & $\mathrm{X}$ & $\begin{array}{l}\text { Doações a instituições de caridade locais; utilização } \\
\text { de energia solar e participação em programa de } \\
\text { segurança de vizinhos protegidos. }\end{array}$ \\
\hline $\begin{array}{l}\text { Hotel } \\
\text { Sorrento }\end{array}$ & & $X$ & & $\mathrm{X}$ & $\begin{array}{l}\text { Economia de água e luz, conscientização dos } \\
\text { hóspedes e participação no Convention\&Visitors } \\
\text { Bureau }\end{array}$ \\
\hline $\begin{array}{l}\text { MK Apart } \\
\text { Hotel }\end{array}$ & & $X$ & & $\mathrm{X}$ & $\begin{array}{l}\text { Economia de água e luz; modernização de } \\
\text { equipamentos; parcerias com instituições sociais. }\end{array}$ \\
\hline $\begin{array}{c}\text { Normandy } \\
\text { Hotel }\end{array}$ & & $X$ & $X$ & $\mathrm{X}$ & $\begin{array}{l}\text { Economia de água e luz; apoio a instituições e } \\
\text { grupos culturais, conscientização dos hóspedes. }\end{array}$ \\
\hline $\begin{array}{l}\text { Ouro } \\
\text { Minas } \\
\text { Palace } \\
\text { Hotel }\end{array}$ & $X$ & $\mathrm{X}$ & $X$ & $\mathrm{X}$ & $\begin{array}{l}\text { Promoção da cultura e comunidade local; apoio a } \\
\text { grupos culturais; doação a instituições de caridade, } \\
\text { reciclagem de resíduos sólidos e economia de água } \\
\text { e luz. }\end{array}$ \\
\hline $\begin{array}{l}\text { Pampulha } \\
\text { Flat }\end{array}$ & $X$ & & & $\mathrm{X}$ & $\begin{array}{l}\text { Qualificação de equipe em cursos locais; economia } \\
\text { de luz e reciclagem. }\end{array}$ \\
\hline $\begin{array}{c}\text { Via } \\
\text { Contorno } \\
\text { Hotel } \\
\end{array}$ & & $\mathrm{X}$ & & $X$ & $\begin{array}{l}\text { Economia de luz e água; apoio a instituições de } \\
\text { caridade; conscientização dos hóspedes; } \\
\text { acessibilidade em quarto e áreas comuns. }\end{array}$ \\
\hline
\end{tabular}

Fonte: Autores. 
Ao avaliar criticamente os discursos explicitados e pronunciados, a principal conclusão sobre o discurso não dito é que quando existe a preocupação dos gestores dos meios de hospedagem pesquisados sobre Responsabilidade Social, essa preocupação é secundária. Além disso, dentre os hotéis que estavam praticando alguma iniciativa sustentável, os gestores não estavam considerando as áreas de atuação como um todo (Econômica, Social, Cultural e Ambiental) como sugerem diversos autores (HOFFMANN; BRAGUIROLLI; CAMPOS, 2010; SOARES; SOUSA, 2010) e o enfoque estava ocorrendo primordialmente em medidas pontuais, sobretudo de cunho ambiental.

Fatores de gestão internos aos hotéis como manutenção e investimento em equipamentos e qualificação da mão de obra poderiam estar conectados com estratégias de responsabilidade dos empreendimentos, conforme Ribeiro (2008) e Coelho (2009), mas não foi o que se observou no discurso pronunciado dos hoteleiros.

Os responsáveis pelos hotéis demonstraram possuir noção da importância do tema, mas o mesmo não era enfatizado quando relacionado à competitividade. Em geral, constatou-se que os hoteleiros não enfatizavam as ações de responsabilidade social como estratégias que possibilitavam a melhoria da competitividade do empreendimento, embora algumas ações desenvolvidas no âmbito ambiental já possuam essa interação com o desempenho operacional no sentido de reduzir gastos e poupar para o hotel como sugerido por Souza e Ferreira (2010). Esse resultado demonstra que a gestão hoteleira estudada, em geral ainda não adotou a mudança sugerida por Munck, Munck e Borimde Souza (2011) rumo a uma sustentabilidade que vai além da financeira e caminha à favor das Pessoas, do Planeta e do Lucro.

Souza e Ferreira (2010) afirmam que pouco se estuda sobre o comportamento do brasileiro sobre sua preferência ou não por organizações socialmente responsáveis, ao escolher a empresa. Contudo, esse estudo demonstra que no setor hoteleiro estudado a situação é ainda mais alarmante, pois as informações sobre as ações de responsabilidade social das empresas não está ao alcance dos potenciais clientes nos meios de divulgação formais da empresa. Isto é, uma vez que esta informação não está disponível no ato da reserva do hotel, ela passa a ser uma informação que não possibilita a opção do hóspede por hotéis mais responsáveis. 
No entanto, é possível que não haja cobrança ou preocupação dos clientes sobre esses aspectos, uma vez que outros valores como localização e qualidade do serviço podem possuir maior peso para a escolha dos clientes como sugere Xiao, O’Neill e Mattila (2012). Pesquisas sobre satisfação do cliente que utilizam serviços hoteleiros afirmam que os principais atributos que influenciam a escolha desses consumidores são localização conveniente e serviço de qualidade (BRANCO; RIBEIRO; TINOCO, 2010).

Ainda, Branco, Ribeiro e Tinoco (2010, p. 580) alegam em sua pesquisa que $56 \%$ da satisfação do cliente em serviços de hotelaria são relativos à qualidade do quarto do hotel, cordialidade do pessoal, qualidade do restaurante e preço pago comparado com a qualidade recebida. Isso indica que a satisfação dos hóspedes de serviços de hotelaria também não tem considerado a responsabilidade social como relevante para a escolha do hotel. Nesse sentido, não há indícios de que a Responsabilidade Social esteja gerando retorno econômico satisfatório para o setor hoteleiro o que pode explicar a consideração do tema como secundário para os gestores responsáveis pelos hotéis pesquisados.

Finalmente, não é possível afirmar que as estratégias sustentáveis dos hotéis em rede se diferenciam em termos de qualidade das estratégias dos hotéis individuais. Contudo, a partir de uma visão mais global, percebeu-se que as ações de responsabilidade social corporativa das redes possuem um caráter mais formalizado e amplo que podem resultar em benefícios para o hotel e o destino turístico.

Já na perspectiva dos gestores dos hotéis individuais, as ações de responsabilidade social corporativa possuem uma relação mais íntima com o destino, além de proximidade com a história e identidade do empreendimento, apresentando-se de maneiras mais específicas e inseridas no contexto local. Assim, os hotéis individuais utilizam as ações de responsabilidade social corporativa como forma de diferenciar o hotel e ressaltar suas idiossincrasias. Conforme cita Proserpio (2007) esse pode ser um exemplo de como os hotéis individuais podem buscar se diferenciarem das redes para garantirem sua competitividade no mercado. 


\section{CONSIDERAÇÕES FINAIS}

Assim como encontrado por Merwe e Wöcke (2007) em hotéis da África do Sul, as ações que envolvem a responsabilidade social corporativa nos hotéis de Belo Horizonte variam no grau o qual cada hotel implementa suas atividades, apresentandose de forma pontual e desarticulada com estratégias de competitividade. Nesse trabalho, considerou-se que os hotéis que possuem mais alto grau de ações de responsabilidade social corporativa e sustentabilidade são aqueles que apresentaram atividades diversificadas e abrangeram o maior número de dimensões (econômica, social, cultural e ambiental).

A organização em redes e franquias é mais uma das tendências do setor hoteleiro e tais formas de gestão ressaltam a competitividade superior dos hotéis em rede quando comparados a hotéis individuais, possuindo maior poder de divulgação e marketing, além de investimentos diversos como gestão de pessoas por meio de treinamento, seleção e qualificação dos profisssionais e controle da qualidade do serviço como ressalta Proserpio (2007).

Por outro lado, o papel do proprietário de hotéis individuais está intimamente ligado com o desempenho apresentado pelo hotel (XIAO; O’NEILL; MATTILA, 2012) e as decisões tomadas em hotéis individuais devem caminhar no sentido de se diferenciarem dos hotéis em rede. Deste modo, a responsabilidade social corporativa pode ser utilizada como forma de gerar vantagem competitiva superior uma vez que a particularidade e a história de hotéis individuais se apresentaram como fatores de maior força social e cultural quando comparadas a empreendimentos que apresentaram estratégias de sustentabilidade comum a todos os hotéis de uma mesma rede.

Ao considerar as dimensões da vantagem competitiva sugeridas por Girón, Hernández e Castillo (2008) para o contexto de redes hoteleiras a citar, rentabilidade, satisfação do consumidor, participação no mercado e inimitabilidade, a responsabilidade social corporativa ainda precisa percorrer um longo caminho para reconfigurar a competitividade nos meios de hospedagem.

Apesar de se apresentar como um campo repleto de desafios para os hoteleiros, a área é promissora para a competitividade se levada em consideração a possibilidade de inovação e implementação de estratégias que impactem na satisfação do cliente, 
resultem em rentabilidade e ainda se diferenciem das ações dos concorrentes, dificultando a imitação dos competidores. Contudo, apenas preocupações ambientais podem não gerar retorno satisfatório para a competitividade dos hotéis. Por isso, é necessário que os hoteleiros utilizem a amplitude que o tema responsabilidade social corporativa pode oferecer para a geração de competitividade.

Em relação a implicações gerenciais, é importante que os dirigentes hoteleiros passem a pensar a sustentabilidade e a responsabilidade social corporativa em todas as suas dimensões. Além disso, alinhar essas estratégias com objetivos sociais e empresariais bem definidos, como sugere Porter e Kramer (2005), é outro importante desafio para os hotéis. Em relação à competitividade, a possibilidade dos meios de hospedagem tornar mais claras e visíveis suas ações de responsabilidade social corporativa pode contribuir para fatores como a redução de gastos e preservação da imagem institucional da empresa, conforme proposto por Souza e Ferreira (2010).

Dentre as limitações de pesquisa, em função do caráter qualitativo da mesma, considera-se não ser possível generalizar as proposições sobre as medidas desenvolvidas em hotéis de Belo Horizonte, tampouco para a hotelaria de outras regiões. Ainda, em função das entrevistas, essa pesquisa fica sujeita à opinião expressa pelos entrevistados, podendo não se tratar da visão oficial ou global do hotel.

Para pesquisas futuras sugere-se aprofundar o estudo em relação aos impactos financeiros ao se investir em responsabilidade social corporativa nos hotéis e estender a pesquisa para o desempenho organizacional. Há a possibilidade de que a Responsabilidade Social Corporativa não tenha um peso significativo na satisfação do hóspede, tema que pode ser abrangido em pesquisas futuras. Outro ponto do discurso não dito que não foi ênfase desse trabalho, se relaciona a aspectos éticos e a transparência da gestão interna dos hotéis. Conforme menciona Menicucci (2007), é comum a rotatividade em meio hoteleiros em função da insatisfação dos funcionários, com isso, é preciso investigar mais a fundo se aspectos éticos dos hotéis não podem contribuir para sua competitividade, tendo em vista a Responsabilidade Social Corporativa como pano de fundo. 


\section{REFERÊNCIAS}

ABIH MG. Associação Brasileira da Indústria de Hotéis de Minas Gerais.

Disponível em: <http://www.abihmg.com.br/abih_novo/associados2.asp>. Acesso em: 17/07/2013.

AVSI. Regulação Legislativa da Responsabilidade Social Corporativa e do Terceiro Setor. Conceitos e Legislação. Belo Horizonte: Fundação AVSI, 2011.

BARNEY, J. B.; CLARK, D. N. Resource-Based Theory: Creating and sustaining Competitive Advantage. New York: Oxford University, 2007.

BH C\&VB. Belo Horizonte Convention\&Visitors Bureau.

Disponível em <http://www.bhcvb.com.br/associados/>. Acesso em: 17/07/2013.

BORGES, M. P. Sustentabilidade e Competitividade: Águas de São Pedro. In: PHILIPPI Jr., A.; RUSCHMANN, D. v. d. M. (Edit.). Gestão Ambiental e Sustentabilidade no Turismo. Barueri - São Paulo: Manole, 2010, p. 871-888.

BRANCO, G. M.; RIBEIRO, J. L. D.; TINOCO, M. A. C. Determinantes da satisfação e atributos da qualidade em serviços de hotelaria. Produção, v. 20, n. 4, p. 576-588, out./dez. 2010.

BRITO, R. P.; BRITO, L. A. L. Vantagem Competitiva, Criação de valor e seus efeitos sobre o Desempenho. RAE, São Paulo, v. 52, n. 1, jan./fev. 2012.

CASTELLS, M. A sociedade em rede. São Paulo: Paz e Terra, 2000.

COELHO, M. F. A Dinâmica do Hipercentro de Belo Horizonte e a Hotelaria: em busca da sustentabilidade local. Monografia (Pós-Graduação em Elaboração, Gestão e Avaliação de Projetos Sociais), Faculdade de Filosofia e Ciências Humanas. Universidade Federal de Minas Gerais. Belo Horizonte, 2009.

DAFT, R. L. Administração. 4. ed. Rio de Janeiro: LTC,1999.

FERRELL, O. C.; FRAEDRICH, J.; FERRELL, L. Business ethics: ethical decision making and cases. Boston: Houghton Mifflin, (4th ed.), 2000.

FLECHA, B. Responsabilidade Social e Desenvolvimento Sustentável. Belo Horizonte: do autor, 2007.

GAMEIRO, P. A. D. As organizações em rede. Lisboa: Universidade Lusófona de Humanidades e Tecnologias, 2008. Disponível em: <http://www.bocc.ubi.pt/pag/gameiro-paulo-as-organizacoes-em-rede.pdf>. Acesso em: 19/06/2012. 
GIRÓN, J. P. H.; HERNÁNDEZ, M. L. D.; CASTILLO, D. I. Ventaja competitiva sostenible en pequeñas y medianas empresas hoteleras del sur de México. Pensamiento \& Gestión, n. 25, Universidad del Norte, p. 161-177, 2008.

HANDY, C. Para que serve uma empresa? In: RODRIGUEZ, M. V. R. (org.) Ética e Responsabilidade Social nas Empresas. Rio de Janeiro: Elsevier, 2005. p. 118-133.

HITT; M. A.; IRELAND, R. D.; HOSKISSON, R. E. Administração Estratégica. São Paulo: Pioneira Thomson Learing, 2003.

HOFFMANN, H. E.; BRAGHIROLLI, C.; CAMPOS, L. M. S. Redes de empresas e Instituições de Suporte ao Turismo: Teoria e Prática. In: PHILIPPI Jr., A.; RUSCHMANN, D. v. d. M. (edit.). Gestão Ambiental e Sustentabilidade no Turismo. Barueri - São Paulo: Manole, 2010. p. 575-601.

HOLJEVAC, I. A. Work Productivity in the Croatian Hotel Industry - Fundamentals and Concepts for Achieving Growth and Competitiveness. South East European Journal of Economics \& Business, Sarajevo, v. 5, n. 1, p. 85-90, April 2010.

HSIEH, E. Hospitalidade e Sustentabilidade. In: PHILIPPI Jr., A.; RUSCHMANN, D. v. d. M. (edit.). Gestão Ambiental e Sustentabilidade no Turismo. Barueri - São Paulo: Manole, 2010. p. 97-108.

IONCICA, M.; TALA, M.; BRINDUSOIU, C.; IONCICA, D. The Factors of Competitiveness in the Hospitality Industry and the Competitive Strategy of Firms. Economic Science Series, Oradea, v. 17, n. 2, p. 212 -218, June 2008.

KAKU, R. The Path of Kyosei. Harvard Business Review, p. 55-63, July-August 1997.

KEINERT, T. M. M. Sustentabilidade Caminho ou Utopia? RAC, Curitiba, v. 12, n. 2, p. 575-577, abr./jun. 2008.

MENICUCCI, C. M. B. F. Rotatividade na hotelaria econômica. Uma investigação nos hotéis Ibis de Belo Horizonte e Betim. Dissertação (Mestrado em Turismo e Meio Ambiente) Centro Universitário UNA. Belo Horizonte, 2007.

MERWE, M. V. D.; WÖCKE, A. An investigation into responsible tourism practices in the South African hotel industry. South African Journal Business Management, v. 2, n. 38, 2007.

MUNCK, L.; MUNCK, M. G. M.; BORIM-DE-SOUZA, R. Sustentabilidade Organizacional: A proposição de uma Framework Representativa do Agir Competente para seu Acontecimento. Revista Interinstitucional de Psicologia, v. 4, n. 2, p. 147158, dez. 2011. Edição Especial. 
OLIVEIRA, M. F.; GONÇALVES, C. A. Estratégia Cooperativa em Redes Organizacionais: Um Estudo em Polo Turístico de Minas Gerais. Revista IberoAmericana de Estratégia - RIAE, São Paulo, v. 10, n. 2, p. 34-57, maio/ago. 2011.

PORTER, M. E. Clusters and the new economics of competition. Harvard Business Review, p. 77-90, nov./dez., 1998.

PORTER, M. E.; KRAMER, M. R. A Vantagem Competitiva da Filantropia Corporativa. In: RODRIGUEZ, M. V. R. (Org.) Ética e Responsabilidade Social nas Empresas. Rio de Janeiro: Elsevier, 2005.

PROSERPIO, R. O Avanço das Redes Hoteleiras Internacionais no Brasil. São Paulo: Aleph, 2007.

RIBEIRO, J. F. Gestão Ambiental e Endomarketing na Hotelaria: Estudo de Caso Delta Sun Peaks Resort. Monografia (Graduação em Turismo), Instituto de Geociências, Universidade Federal de Minas Gerais. Belo Horizonte, 2008.

SCHROEDER, J. T; SCHROEDER, I. Responsabilidade Social Corporativa: Limites e Possibilidades, RAE-eletrônica, v. 3, n. 1, Art. 1, jan./jun., 2004.

SERPA, D. A. F.; FOURNEAU, L. F. Responsabilidade Social Corporativa: uma Investigaçăo sobre a percepção do consumidor. RAC, v. 11, n. 3, p. 83-103, jul./set. 2007.

SHAH, K. U. Strategic organizational drivers of corporate environmental responsibility in the Caribbean hotel industry. Policy Sciences, v. 44, n. 4, p. 321- 344, nov. 2011.

SOARES, G. M. P. Responsabilidade Social Corporativa: Por uma Boa Causa? RAEeletrônica, v. 3, n. 2, Art. 23, jul./dez., 2004.

SOARES, S. R.; SOUSA, S. R. Aplicação da Análise Multicritério para Avaliação da Sustentabilidade em Empreendimentos Turísticos. In: PHILIPPI Jr., A.; RUSCHMANN, D. v. d. M. (Edit.). Gestão Ambiental e Sustentabilidade no Turismo. Barueri - São Paulo: Manole, 2010. p. 203-232.

SOUZA, M. J. B.; FERREIRA, E. Responsabilidade Social em Organizações Turísticas. In: PHILIPPI Jr., A.; RUSCHMANN, D. v. d, M. (Ed.). Gestão Ambiental e Sustentabilidade no Turismo. Barueri - São Paulo: Manole, 2010. p. 755-773.

TEODÓSIO, A. S. S.; BARBIERI, J. C; CSILlAG, J. M. Sustentabilidade e Competitividade: Novas Fronteiras a partir da Gestão Ambiental. Revistas Gerenciais, São Paulo, v. 5, n. 1, p. 37-49, jan./jun., 2006.

TUNG, G.-S.; CHENG, T.-M.; WU, L.-C. The Measurement of Competitiveness of International Tourist Hotels in Taiwan. Journal of International Management Studies, v. 4, n. 2, p. 41-49, Aug. 2009. 
VARGAS, E. E; ZIZUMBO, L.; VIESCA, F. C.; SERRANO, R. C. Gestión ambiental enel sector turístico mexicano. Efectos de La regulación em El desempeño hotelero. Cuad. admon.ser.organ., Bogotá, v. 24, n. 42, p. 183-204, enero/junio, 2011.

VIERA, E. V.; HOFFMANN, V. E. Atores e práticas de Sustentabilidade Ambiental em Empreendimentos Hoteleiros. In: PHILIPPI Jr., A.; RUSCHMANN, D. v. d. M. (Edit.). Gestão Ambiental e Sustentabilidade no Turismo. Barueri - São Paulo: Manole, 2010. p. 603-631.

XIAO, Q.; O'NEILL, J. W.; MATTILA, A. S. The role of hotel owners: the influence of corporate strategies on hotel performance, International Journal of Contemporary Hospitality Management, v. 24, n. 1, p. 122 -139, 2012.

Recebido em: 04-07-2012 (primeira versão).

Recebido em: 29-01-2013 (segunda versão).

Aceito para publicação em: 28-02-2103. 